Noticias

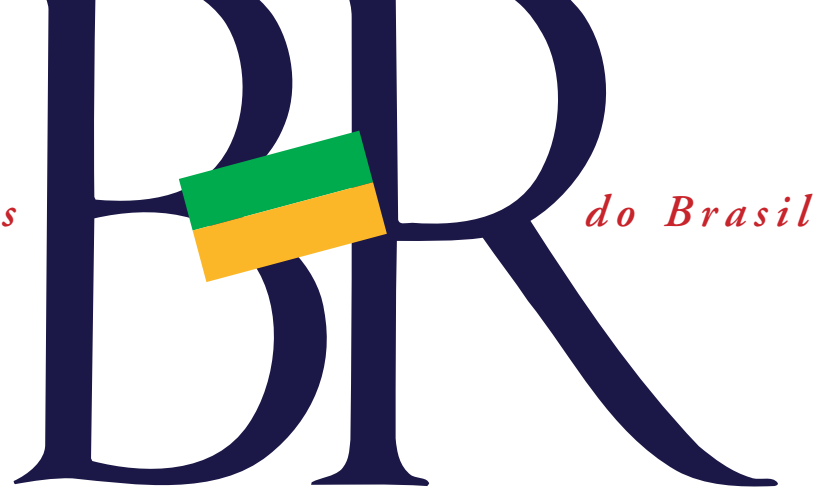

EDUCAÇÃO AMBIENTAL

\title{
0 olhar dos jovens sobre a problemática ambiental
}

Como os jovens percebem relações de causa-efeito e conceitos ligados à sustentabilidade ambiental? Este é o objetodeestudodaequipedoprojeto "(Re)Conectando o nexo: experiências e aprendizado de jovens brasileiros sobre alimentos-água-energia”, desenvolvido por meio de uma parceria entre a Faculdade de Engenharia de Guaratinguetá, (FEG/Unesp) e a Universidade de Birmingham, no Reino Unido. É um projeto temático co-financiado pela Fundação de Amparo à Pesquisa do Estado de São Paulo (Fapesp) e pelo Conselho de Pesquisa Econômica e Social do Reino Unido (ESRC, na sigla em inglês). A pesquisa consiste na coleta e análise de dados sobre a percepção de jovens com idades entre 10 e 24 anos quanto ao consumo e a interconexão entre água, alimentos e energia. Eles moram na região do Vale do Paraíba, no estado de São Paulo. A partir dessa análise, a equipe de pesquisa pretende traçar um diagnóstico que propicie a elaboração de políticas públicas para estimular a consciência ambiental entre os jovens que, futuramente, serão os tomadores de decisões para lidar com a crise ambiental. "Trata-se de

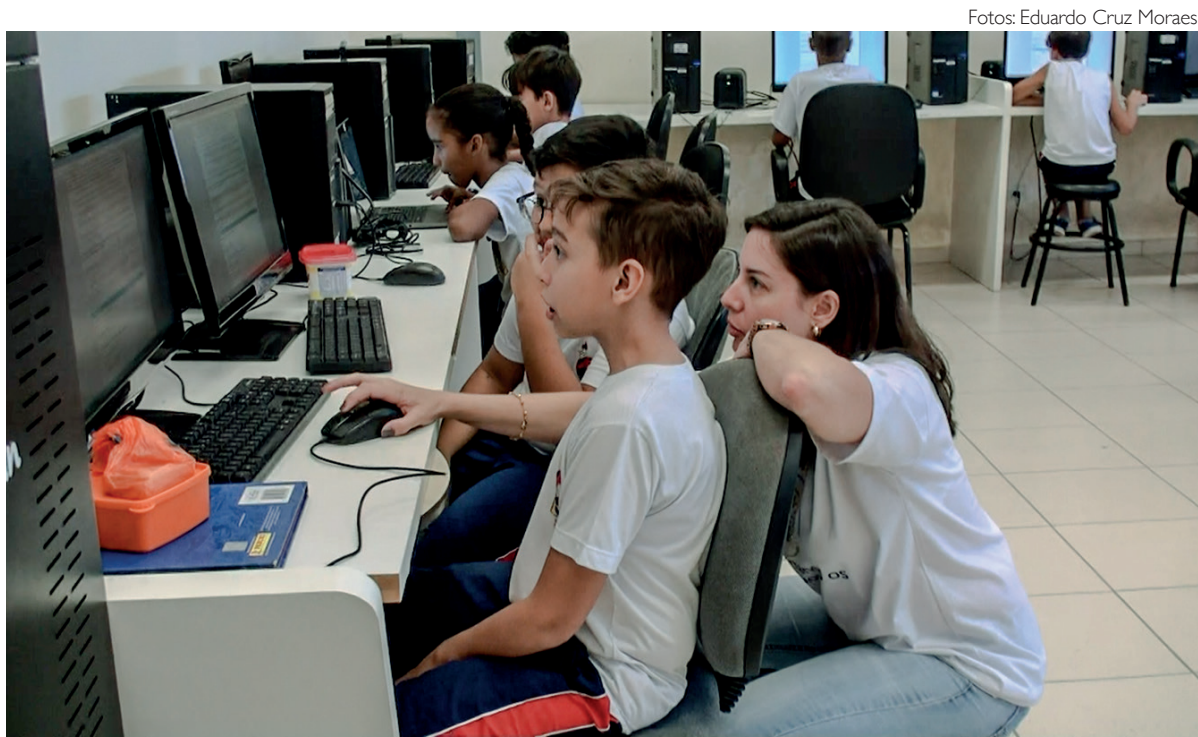

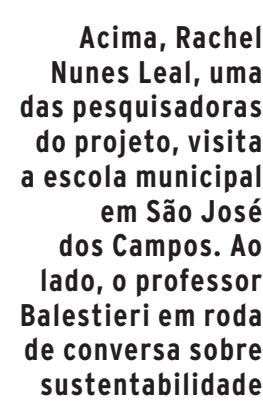

um projeto multidisciplinar, com profissionais da área de biologia, geologia e educação", explica o engenheiro e coordenador do projeto, José Antônio Perrella Balestieri.

O projeto surgiu a partir do encontro dos engenheiros da Unesp com um grupo de cientistas sociais do Reino Unido, em 2015. "Nós fazí- amos parte de um projeto sobre o planejamento sustentável de cidades. No entanto, como engenheiros, nos limitávamos a questões de natureza técnica da sustentabilidade. Já o foco de pesquisa dos ingleses era entender como jovens percebem, aprendem e querem contribuir com práticas mais sus- 
impactar outras. É a relação de dependência que temos entre estes três elementos - água, alimento e energia - e de como o uso de um impacta nos outros", explica Balestieri. A abordagem da pesquisa a partir do conceito do nexo tem por objetivo lidar com a questão ambiental de uma maneira sistêmica, levando em consideração os diversos fatores envolvidos e as relações de trade off (de causas e consequências) entre eles.

CONSTRUINDO ESPAÇOS DE INTEGRAÇÃo A natureza sistêmica não se limita somente ao objeto de pesquisa, mas também às ações que necessitam ser implementadas para se abordar a questão da sustentabilidade nos ambientes de ensino. A discussão do tema sustentabilidade ambiental começou a ganhar visibilidade a partir da segunda metade do século XX. No entanto, mesmo após mais de meio século e com estudos cada vez mais relacionando a atividade humana a distúrbios no meio ambiente, o tema tem sido pouco abordado no ensino ou abordado de maneira superficial. O próprio conceito de sustentabilidade passou por uma apropriação e banalização pelo mercado, fenômeno que é chamado de green washing quando empresas vendem a imagem de responsabilidade socioambiental sem, necessariamente, estarem de fato engajadas em tais práticas. Os pesquisadores Fernan- do Antonio dos Santos Fernandez, Pâmela Castro Antunes, Leandro Macedo e Carlos André Zucco, do Departamento de Ecologia da Universidade Federal do Rio de Janeiro (UFRJ), avaliaram 126 estudos sobre práticas de extrativismo feitas no Brasil e concluíram que quase a metade delas $(48,4 \%)$ eram insustentáveis do ponto de vista ambiental (Natureza\&Conservação, 10(1):77-82, jul. 2012).

Para que haja de fato a mobilização da opinião pública na adoção de atitudes que sejam verdadeiramente sustentáveis, além de um trabalho de educação ambiental nas bases de ensino, é preciso formar profissionais nas instituições de ensino superior do país comprometidos com a questão da preservação do meio ambiente. Pensando nisso, a equipe do projeto "(Re)Conectando o nexo" realizou, em dezembro de 2018 , uma roda de discussão com o tema "Ensino-aprendizagem de questôes ambientais e de sustentabilidade como temas transversais: relatos de experiências e desafios futuros". O convite foi feito a professores e estudantes para discutirem como criar espaços de integração e ações de ensino para abordar a temática ambiental dentro dos cursos da FEG/Unesp. "O objetivo do projeto é construir políticas públicas e não dá para fazer isso sem falar com o outro, para o outro e sobre do outro", acredita o professor Paulo Vallada- res, geólogo, professor do curso de engenharia civil da FEG/Unesp e integrante da equipe do projeto.

A discussão foi norteada pela pergunta: nossos alunos estão sendo formados sobre questôes relacionadas à sustentabilidade? Uma das questôes chave diz respeito à quebra de paradigma de um tipo de educação de caráter "conteudista" do ensino médio e que visa a quase somente preparar os alunos para serem aprovados no vestibular. "Há conteúdo, mas falta contextualização. Aí entra o professor como agente que irá integrar esse conteúdo à experiência do aluno, para chegar em um conhecimento sistematizado", apontou Rubens Alves Dias, professor da FEG/Unesp e especialista na área de educação para a engenharia. A psicóloga e coordenadora do curso de engenharia de produção, Andreia Maria Salgado, complementa este ponto: "Não estamos formando pessoas críticas e não dá para pensar em sustentabilidade sem criticidade". A criação de espaços de discussão como esses é uma iniciativa essencial se pretendemos despertar mudanças de conduta no ensino superior. Novos encontros devem ser organizados pela equipe do projeto "(Re)Conectando o nexo" para engajar professores, alunos e coordenadores de cursos a discutir os caminhos para essa mudança.

Eduardo Cruz Moraes 